\title{
USO DE GEOESTATÍSTICA NA CORRELAÇÃO ENTRE GRAUS DE VULNERABILIDADE E FRAGILIDADE AMBIENTAIS ASSOCIADOS À INTENSIDADE PLUVIOMÉTRICA E EROSIVIDADE DAS CHUVAS EM PARTE DA REGIÃO SUDESTE E CENTRO-SUL MATOGROSSENSE
}

\author{
Alesson Pires Maciel Guirra ${ }^{(a)}$, Caio Augusto Marques dos Santos ${ }^{(b)}$ \\ (a) Mestrando do Programa de Pós-Graduação em Geografia, Universidade Federal de Mato Grosso - Campus \\ Universitário de Rondonópolis, engeoguirra@gmail.com \\ (b) Professor do Programa de Pós-Graduação em Geografia, Universidade Federal de Mato Grosso - Campus \\ Universitário de Rondonópolis, kiomarques@ hotmail.com
}

\section{Eixo: Climatologia em diferentes níveis escalares: Mudanças e Variabilidades}

\begin{abstract}
Resumo
A intensidade pluviométrica constitui-se numa variável climática importante para diagnósticos de vulnerabilidade e fragilidade ambientais, haja visto o seu potencial de erosividade, tornando-se necessário espacializar a forma de sua ocorrência numa determinada região. Objetiva-se identificar o interpolador geoestatístico que melhor espacializa as intensidades pluviométricas e, a partir dele, interpolar as demais variáveis: precipitação média mensal e anual, coeficiente de chuva e erosividade, com a finalidade de entender como estas se correlacionam na área de estudo. Verificou-se que o topoto-raster se apresentou como o mais adequado na delimitação das isoetas, ajustando-se melhor aos compartimentos morfoesculturais e suas respectivas variações altimétricas, bem como a vulnerabilidade e a fragilidade apresentaram-se diretamente proporcionais a precipitações médias mensal e anual, enquanto que o coeficiente de chuva e a erosividade apresentaram padrões distintos, demonstrando que as equações condicionam contornos de isoetas que não se relacionam diretamente com as morfoesculturas existentes entre planaltos, depressões interplanálticas e planícies.
\end{abstract}

Palavras chave: intensidade pluviométrica, geoestatística, vulnerabilidade, Mato Grosso.

\section{Introdução}

A intensidade pluviométrica de uma dada região é uma variável relevante para projetos de infraestutura e ordenamento de uso e ocupação do solo, que visam adequar-se de forma mais acertada as potencialidades de erosividade da mesma. Nesse contexto, objetiva-se identificar o interpolador mais adequado para se aplicar na área de estudo na espacialização da vulnerabilidade e fragilidade ambientias associadas à intensidade pluviométrica e, a partir disto, entender como os demais parâmetros de precipitação da chuva: precipitação média mensal e anual, coeficiente de chuva e erosividade anual se relacionam entre si.

Vários autores apresentaram validações para interpoladores geoestatísticos em análises pluviométricas no Brasil, entre eles: Mello et al. (2003), Souza et al. (2011), Marcuzzo, Andrade e Melo (2011), Carvalho, Assad e Pinto (2012), Lucas et al. (2013), entre outros. 
Carvalho, Assad e Pinto (2012) avaliam que tanto o setor público como a adminstração privada têm exigido informações metereológicas e climáticas mais precisas e confiáveis para estabelecer metas, formular o planejamento estratégico e minimizar custos, entretanto verifica-se pouca disponibilidade de dados, ou sua inexistência, em algumas áreas do país, tal como o estado de Mato Grosso.

Crepani et al. (2001) propõe o diagnóstico de vulnerabilidade natural à perda de solo para subsidiar o Zoneamento Ecológico-Econômico utilizando imagens de satélites, estabelecendo para o tema clima valores relativos e empíricos à intensidade pluviométrica. Ross (1994), ao propor análise empírica da fragilidade dos ambientes naturais e antropizados, discorre sobre o índice de erosividade das chuvas (fator E) como um dos parâmetros que compõe a equação universal de perda dos solos (EUPS), podendo esta ser utilizada para análises regionais de fragilidade, no entanto, não estabeleceu uma relação escalar para este elemento climático. A relação existente entre estas duas modalidades de análise ambiental e a evolução metodológica de fragilidade ambiental complementada e adaptada até o presente podem ser melhor compreendidas no trabalho de Guirra, Santos e Nogueira (2016), os quais discorrem como as geotecnologias vêm contribuindo para um diagnóstico mais fiel e adequado à realidade de cada região.

O valor da intensidade pluviométrica segundo Crepani et al. (2001) é obtido dividindo-se o valor da pluviosidade média anual (em mm) pela duração do período chuvoso (em mêses), sendo que para o estado de Mato Grosso, Marcuzzo et al. (2011) determinou em 6 meses (outubro à março) a estação úmida. Neste contexto, propõe-se uma relação entre graus de vulnerabilidade e fragilidade ambientais associados à intensidade pluviométrica, tendo em vista que ambos diagnósticos fundamentam-se nos Princípios de Ecodinâmica de Tricart (1977). Além disto, apresenta-se a relação existente entre vulnerabilidade e erosividade por meio de equações e cartogramas de parte da região sudeste e centro-sul matogrossense.

\section{Área de estudo}

A região deste estudo abrange os limites políticos-administrativos de 9 (nove) municípios do estado do Mato Grosso: Guiratinga, Itiquira, Jaciara, Jucimeira, Pedra Preta, Poxoréu, Rondonópolis, São José do Povo, pertencentes à mesorregião sudeste matogrossense, e Santo Antônio do Leverger, contido na região centrosul do estado, conforme demonstra a carta de localização das estações pluviométricas com suas respectivas fontes e modelo digital de terreno (Figura 1). Esta região, de modo geral, caracteriza-se fisiograficamente por biomas de cerrado, pantanal e resquícios de florestas savânicas nos ambientes de transição e vales fluviais encaixados nos domínios planálticos e interplanálticos. 


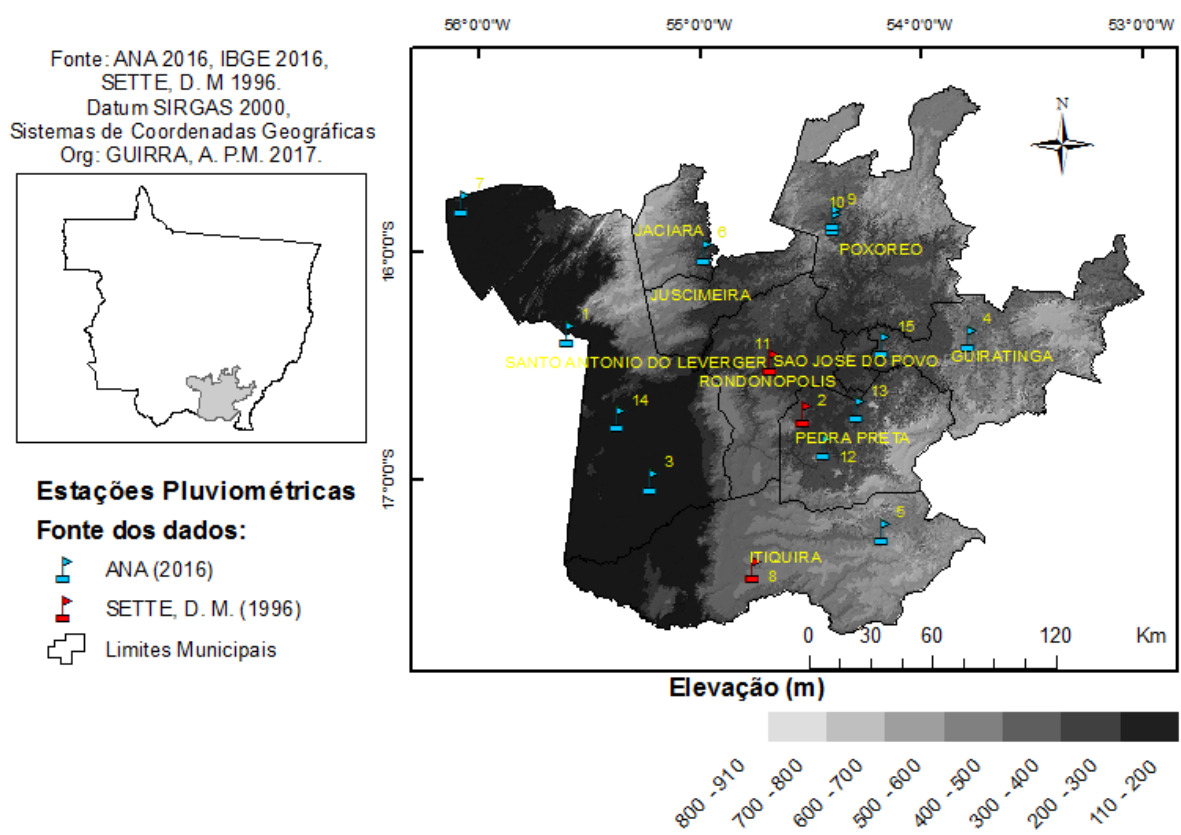

Figura 1 - Localização das estações pluviométricas com suas respectivas fontes de dados e modelo digital de terreno.

Esta região ocupa área equivalente a $45.499,9 \mathrm{Km}^{2}$ e perímetro de $1.763,9 \mathrm{Km}$, sendo escolhida por apresentrar transições entre diferentes compartimentos geomorfológicos de $2^{\circ}$ táxon (morfoesculturas) representadas por planaltos, depressões interplanálticas e planícies (Tabela I).

Tabela I - Compartimentos geomorfológicos de $1^{\circ}$ e $2^{\circ}$ táxon de acordo Ross (1992) e as respectivas intervalos altimétricas expressos em superfície. Baseado no Atlas Socioeconômico-Ecológico de Mato Grosso, conforme SEPLAN-MT (2011).

\begin{tabular}{|ccc|}
\hline MORFOESTRUTURA & MORFOESCULTURA & $\begin{array}{c}\text { INTERVALOS } \\
\text { ALTIMÉTRICOS (m) }\end{array}$ \\
\hline \multirow{2}{*}{$\begin{array}{c}\text { Morfoestruturas dos Sedimentos da Bacia } \\
\text { do Araguaia }\end{array}$} & Pantanal: Planície Fluvial do Araguaia & $100-200$ \\
\cline { 2 - 3 } & $\begin{array}{c}\text { Pantanal: Áreas de Acumulação Inundáveis do } \\
\text { Araguaia }\end{array}$ & $110-200$ \\
\hline \multirow{2}{*}{$\begin{array}{c}\text { Morfoestrutura da Borda Setentrional da } \\
\text { Bacia do Paraná }\end{array}$} & Depressão Interplanáltica de Rondonópolis & $200-400$ \\
\cline { 2 - 3 } & Planalto de Taquari-Alto Itiquira & $400-910$ \\
\cline { 2 - 3 } $\begin{array}{c}\text { Morfoestrutura do Cinturão Orogênico } \\
\text { Paraguai-Araguaia }\end{array}$ & Planalto dos Guimarães & $400-910$ \\
\hline
\end{tabular}

\section{Material e Métodos}

$\mathrm{Na}$ espacialização das intensidades pluviométricas e demais parâmetros climáticos derivados foram utilizados dados de 15 (quinze) estações metereológicas convencionais, 12 (doze) pertencentes à rede 


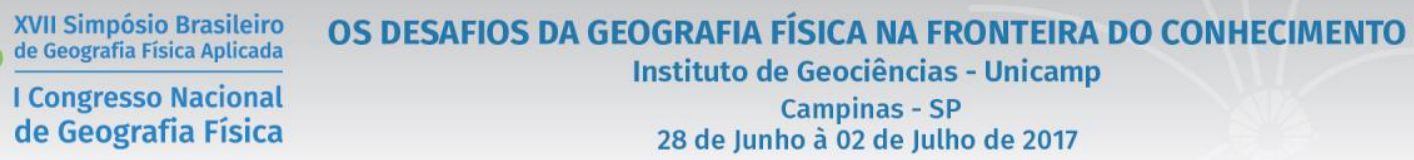

hidrometereológica da Agência Nacional das Águas (ANA) e 3 (três) da Universidade Federal de Mato Grosso/Campus Rondonópolis (UFMT/CUR), oriundo dos dados coletados por Sette (1996). As séries históricas utilizadas abrangem espectro temporal de 02 a 10 anos de observações, abrangendo o período de 1980 a 1990. Ressalta-se que não foi adotado um período-base de estudos para todas as estações, pois ao se analisarem os dados disponíveis, verificou-se não haver registros completos de toda série, não caracterizando um estado médio das precipitações pluviométricas.

Assim, adotou-se como critério o uso dos dados disponíveis para cada estação entre os anos de 1980-1990 por possuir maior quantidade de registros e permitir a complementação com os dados coletados por Sette (1996). Ressalta-se que o objetivo principal é verificar a correlação existente entre os parâmetros de vulnerabilidade, fragilidade e erosividade das chuvas utilizando-se a mesma série de dados, baseando-se nas equações e nos cartogramas obtidos pelo interpolador mais adequado a realidade da área de estudo. A tabela II demonstra as especificações de cada estação utilizada para espacialização das intensidades pluviométricas.

Tabela II - Caracterização das estações pluviométricas selecionadas neste estudo.

\begin{tabular}{|c|c|c|c|c|c|c|c|}
\hline Estação & Município & Código & $\begin{array}{l}\text { Altitude } \\
(\mathrm{m})\end{array}$ & $\begin{array}{l}\text { Latitude } \\
\text { (S) graus }\end{array}$ & $\begin{array}{l}\text { Longitude } \\
\text { (W) graus }\end{array}$ & Período & $\begin{array}{l}\mathrm{N}^{\circ} \mathrm{de} \\
\text { Anos }\end{array}$ \\
\hline Baia Nova & $\begin{array}{c}\text { Santo Antônio do } \\
\text { Leveger/ Barão do } \\
\text { Melgaço }\end{array}$ & 1655000 & 183 & -16356057 & -55586397 & $\begin{array}{l}1980- \\
1988\end{array}$ & 8 \\
\hline $\begin{array}{l}\text { Fazenda São } \\
\text { Benedito }\end{array}$ & Pedra Preta & NULL & 239 & -16689843 & -5454004 & $\begin{array}{l}1980- \\
1990\end{array}$ & 11 \\
\hline Formosa & $\begin{array}{l}\text { Santo Antônio do } \\
\text { Leveger }\end{array}$ & 1755002 & 234 & -16999999 & -55200257 & $\begin{array}{l}1980- \\
1981\end{array}$ & 2 \\
\hline Guiratinga & Guiratinga & 1653002 & 290 & -16352727 & -53760844 & $\begin{array}{c}1980- \\
1990 \\
\end{array}$ & 11 \\
\hline Itiquira & Itiquira & 1754000 & 314 & -17207469 & -54140253 & $\begin{array}{l}1980- \\
1990\end{array}$ & 11 \\
\hline Jaciara & Jaciara & 1554006 & 267 & -15988772 & -54968549 & $\begin{array}{l}1980- \\
1989\end{array}$ & 11 \\
\hline $\begin{array}{c}\text { Padre Ricardo } \\
\text { Remmeter }\end{array}$ & $\begin{array}{c}\text { Santo Antônio do } \\
\text { Leveger }\end{array}$ & 1556008 & 135 & -15783579 & -56068726 & $\begin{array}{l}1987- \\
1990 \\
\end{array}$ & 4 \\
\hline $\begin{array}{l}\text { Plantações } \\
\text { Michelin }\end{array}$ & Itiquira & NULL & 307 & -17235516 & -54730273 & $\begin{array}{c}1980- \\
1990 \\
\end{array}$ & 11 \\
\hline Poxoréu & Poxoréu & 1554004 & 291 & -15833258 & -54383261 & $\begin{array}{l}1980- \\
1990\end{array}$ & 11 \\
\hline $\begin{array}{c}\text { Poxoréu } \\
\text { (Externato São } \\
\text { José) }\end{array}$ & Poxoréu & 1554001 & 283 & -15850039 & -54383390 & $\begin{array}{l}1982- \\
1989\end{array}$ & 8 \\
\hline Rondonópolis & Rondonópolis & 1654000 & 238 & -16471399 & -54656722 & $\begin{array}{l}1980- \\
1990\end{array}$ & 11 \\
\hline $\begin{array}{c}\text { Santa } \\
\text { Escolástica }\end{array}$ & Pedra Preta & 1654004 & 230 & -16843095 & -54408356 & $\begin{array}{c}1980- \\
1984 \\
1986- \\
1989\end{array}$ & 9 \\
\hline
\end{tabular}




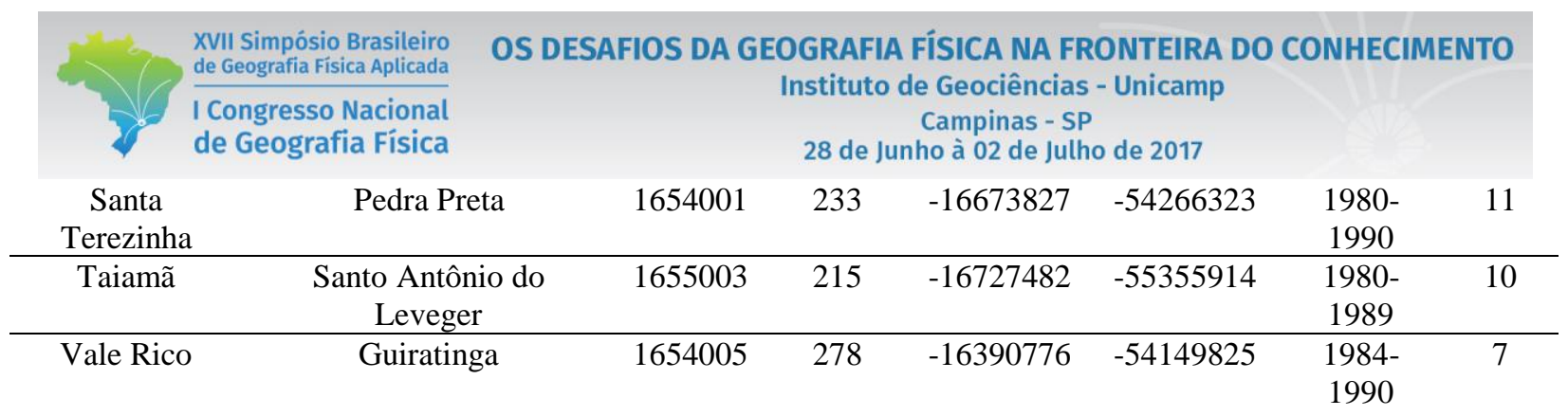

A figura 2 demonstra as principais etapas de todo o processo empregado neste estudo:

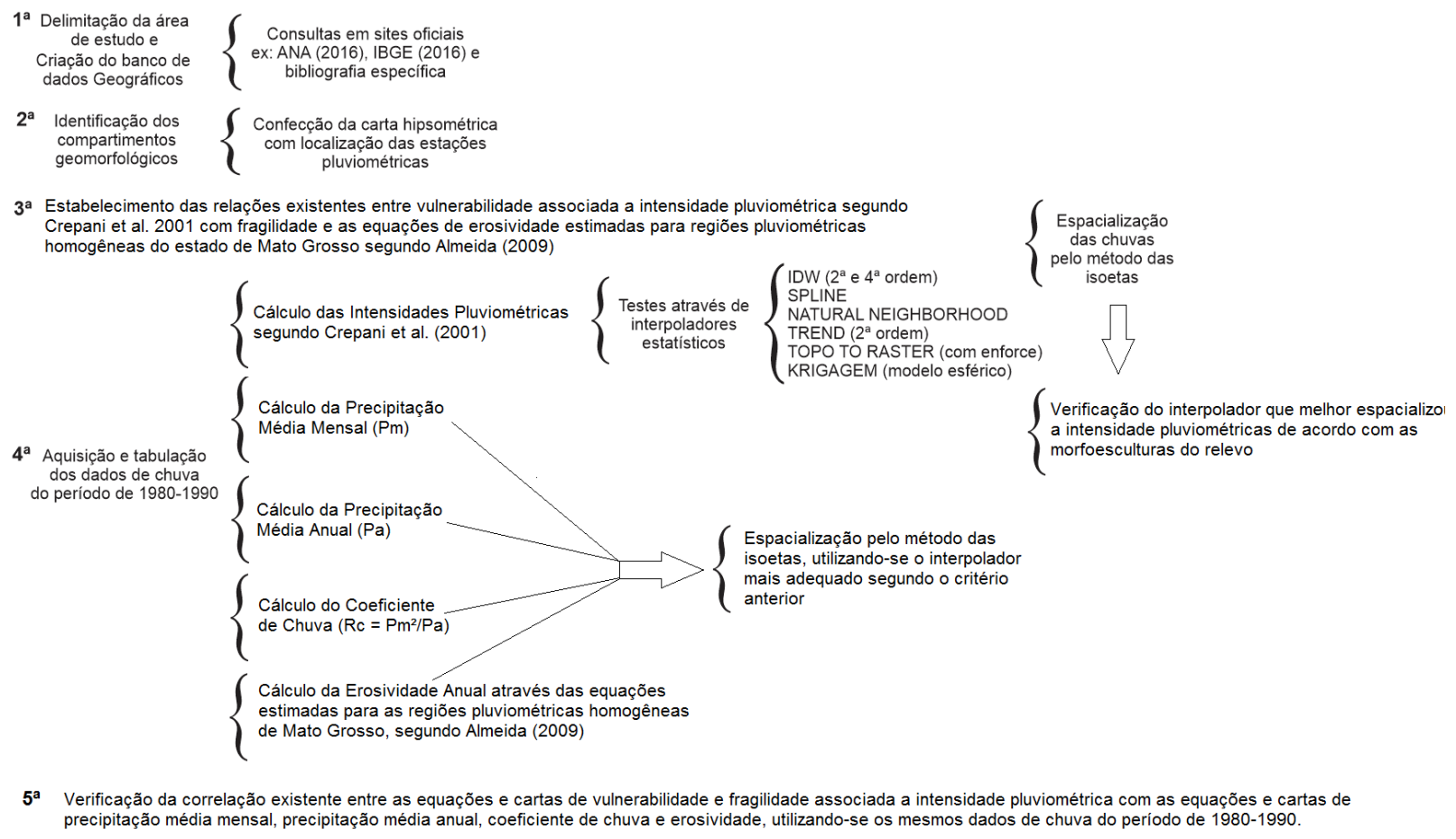

Figura 2 - Esquema metodológico aplicado neste estudo para correlação entre vulnerabilidade e fragilidade ambientias associados à intensidade pluviométrica com parâmetros de erosividade da chuva.

Efetuou-se a interpolação geoestatística das intensidades pluviométricas utilizando-se o método das isoetas disponíveis no Sistema de Informações Geográficas (SIG) ArcGis 10.1 da ESRI (Enviromental Systems Research Institute), afim de identificar o melhor contorno das isolinhas de cada interpolador, tendo-se em vista os compartimentos morfoesculturais existentes. As técnicas de interpolação utilizadas neste estudo foram idw (inverso do quadrado da distância) com potência de $2^{\mathrm{a}}$ ordem, idw com potência de $4^{\mathrm{a}}$ ordem, spline (curvatura mínima), trend (tendência) com potência de $2^{\mathrm{a}}$ ordem, topo-to-raster com enforce e krigagem. Todas as categorias de interpolação foram utilizadas para a espacialização areal de dados pontuais, os quais, nesse caso, estão homogeneamente distribuídos pela área de estudo.

O idw é um dos interpoladores mais utilizados, o qual, segundo Marcuzzo, Andrade e Melo (2011), determina valores dos pontos pela combinação linear ponderada dos pontos amostrados, sendo o peso de DOI - 10.20396/sbgfa.v1i2017.2046 - ISBN 978-85-85369-16-3 


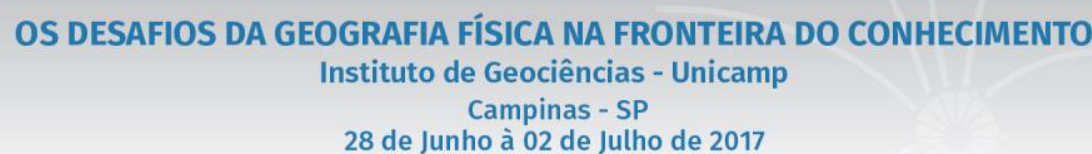

28 de Junho à 02 de Julho de 2017

cada ponto o inverso de uma função da distância. Para Andriotti (2009) apud Souza et al. (2011) o interpolador spline utiliza polinômio para gerar superfície que minimiza a curvatura das isoetas, suavizandoas. O trend, de acordo Lucas et al. (2013) requer uma análise da tendência direcional dos dados espaciais da superfície, representando as variáveis numéricas a partir de regressão polinomial pelo método dos mínimos quadrados, separando os dados em componentes regionais e locais. Hutchison et al. (2009) apud Marcuzzo, Andrade e Melo (2011) afirmam que o interpolador topo-to-raster pode também ser usado para outros tipos de modelo, além dos de elevação, como os de chuva. Para Vieira (2000) e Thompson (1992) apud Mello et al. (2003) a krigagem tem capacidade de produzir melhores estimativas de interpolação, porque está embasada em premissas de não tendenciosidade do estimador e variância mínima da estimativas.

Segundo Salton, Comunello e Fietz (2013) um índice bastante aceito e utilizado para mensurar a capacidade da chuva causar erosão foi proposto por Wischmeier e Smith (1958), que considera a erosividade da chuva como resultado da energia cinética e da intensidade máxima ocorrida em chuvas de 30 minutos, sendo este índice denominado de $\mathrm{EI}_{30}$ (Tabela III, Eq. 1, 2,3 e 4). Lombardi Neto (1977) apud Salton, Comunello e Fietz (2013) propõe a equação do coeficiente de chuva para calcular valores médios mensais e anuais (Tabela III, Eq.5). De acordo com Salton, Comunello e Fietz (2013), Almeida (2009) estimou para a região deste estudo (região pluviométrica homogênea centro e sul de Mato Grosso) duas equações de erosividade (Tabela III, Eq.6 e Eq.7), espacializando-a pelo método da função de base radial.

Nesta conjuntura, depreende-se uma possível relação existente entre a intensidade pluviométrica proposta por Crepani et al. (2001) (Tabela III, Eq.8), com o coeficiente de chuva, tendo-se em vista que a precipitação média anual é uma variável comum entre estas equações, onde isolando-se a variável precipitação média anual obtem-se a Equação 9 da tabela III.

Desta verificação tem-se que a intensidade pluviométrica utilizada nos dignósticos de vulnerabilidade e fragilidade ambientais se relacionam com o coeficiente de chuva de maneira diretamente proporcional e inversamente proporcional a duração da estação úmida, tal como, demonstra a equação 10 da tabela III. Enquanto que, na equação da erosividade estimada para as regiões pluviométricas homogêneas de Mato Grosso, quando se substituiu o coeficiente de chuva pela correspondente de intensidade pluviométrica obtem-se as equações 11 e 12, demonstrando que a erosividade é variável dependente da intensidade pluviométrica, relacionando-se com esta em uma função de base radial para ambas as regiões, centro e sul.

Vale ressaltar que as equações obtidas neste estudo visam demonstrar somente como as equações apresentam relações de proporcionalidade, não assumindo efeito prático para base de cálculo, caso o $R_{c}$ (coeficiente de chuva) seja substituído pelo resultado da equação 10, uma vez que a unidade de medida $\left(\mathrm{mm}^{3} \mathrm{~m}^{-2}\right)$ derivada dessa substituição não apresenta significado climatológico. 
A estimativa dos índices de vulnerabilidade associados à intensidade pluviométrica foi correlacionada qualiquantitativamente dentro da escala de erosividade da chuva, originalmente definida por Crepani et al. (2001), com as classes de fragilidade ambiental para o mesmo tema. Ambas classes apresentam 5 (cinco) parâmetros qualitativos, sendo que a vulnerabilidade pode variar entre estável a vulnerável, enquanto que a fragilidade gradua de muito fraca a muito forte, tal como se observa na tabela IV.

Tabela III - Relação entre parâmetros de intensidade e erosividade da chuva.

\begin{tabular}{|c|c|c|}
\hline $\begin{array}{c}\text { Parâmetros da erosividade mensal, } \\
\text { anual e média e coeficiente de chuva }\end{array}$ & $\begin{array}{l}\text { Parâmetros regionais da chuva } \\
\text { segundo outros autores }\end{array}$ & Significado dos componentes das equações \\
\hline $\begin{array}{l}\text { Energia Cinética da Chuva } \\
\text { segundo Wischmeier e Smith (1958) }\end{array}$ & $\begin{array}{l}\text { Equação estimada para a região } \\
\text { pluviométrica homogênea do Estado de } \\
\text { Mato Grosso segundo Almeida (2009) }\end{array}$ & $\begin{array}{c}E_{c}=\text { é a energia cinética, } \mathrm{MJ} \mathrm{ha}^{-1} \mathrm{~mm}^{-1} ; \\
I_{p}=\text { é a intensidade da precipitação da chuva em } \mathrm{mm} \mathrm{h}^{-1} \text {; }\end{array}$ \\
\hline (Eq. 1) $E C=0,119+0,0873 \times \log \left(I_{p}\right)$ & $\begin{array}{r}\text { (Eq.6) } E I_{30}=244,47 \times R_{c}^{0,508}(\mathrm{Sul}) \\
\text { (Eq.7) } E I_{30}=126,76 \times R_{c}^{0,464} \text { (Centro) }\end{array}$ & $E C_{s}=$ é a energia cinética no segmento de chuva, $\mathrm{MJ} \mathrm{ha}^{-1}$; \\
\hline Energia Cinética no segmento de Chuva & $\begin{array}{c}\text { Duração da estação úmida em Mato Grosso } \\
\text { segundo Marcuzzo et al. (2011) }\end{array}$ & $h=$ é a quantidade de chuva no segmento uniforme, $\mathrm{mm}$; \\
\hline (Eq.2) $E C_{s}=E C \times h$ & $t_{p u}=6$ meses & \multirow{7}{*}{$\begin{array}{l}I_{30}=\text { é a intensidade da chuva em } 30 \text { min consecutivos, } \mathrm{mm} \mathrm{h}^{-1} ; \\
i_{n}=\text { é o valor da intensidade da chuva de ordem n }\left(\mathrm{mm} \mathrm{h}^{-1}\right) \\
\text { ocorrida no intervalo contínuo de } 30 \mathrm{~min} ; \\
t_{n}=\text { é o tempo de ocorrência da intensidade da chuva de ordem n, } \\
\text { ocorrida dentro do intervalo contínuo de } 30 \mathrm{~min} ; \\
E I_{30}=\text { é o índice de erosividade da chuva erosiva individual, } \\
\text { MJ mm ha }{ }^{-1} \mathrm{~h}^{-1} ; \\
R_{C}=\text { é o coeficiente de chuva, mm; } \\
P_{m}=\text { é a precipitação média mensal, mm; } \\
P_{a}=\text { é a precipitação média anual, mm; } \\
I_{v P s}=\text { é a intensidade da chuva no intervalo contínuo de duração } \\
\text { da estação úmida, estabelecido para uma dada região, mm mês }{ }^{-1} ; \\
t_{p u}=\text { é o tempo de duração da estação úmida estabelecido para } \\
\text { uma dada região expressa em mêses. } \\
\text { Obs:. Eq. = Equação }\end{array}$} \\
\hline $\begin{array}{l}\text { Intensidade Máxima da Chuva } \\
\text { em } 30 \text { minutos }\end{array}$ & $\begin{array}{l}\text { Intensidade Pluviométrica } \\
\text { segundo Crepani et al. (2001) }\end{array}$ & \\
\hline (Eq.3) $I_{30}=\sum_{i=1}^{n} i_{n i} \times t_{n i}$ & (Eq. 8) $I_{v p s}=P_{a} / t_{p u}$ & \\
\hline $\begin{array}{l}\text { Índice de Erosividade da } \\
\text { chuva erosiva individual }\end{array}$ & $\begin{array}{l}\text { Relação entre Intensidade Pluviométrica } \\
\text { para estudos de vulnerabilidade e } \\
\text { fragilidade, o coeficiente de chuva e a } \\
\text { erosividade }\end{array}$ & \\
\hline (Eq.4) $E I_{30}=E C_{t} \times I_{30}$ & $\begin{array}{c}\text { Depreende - se neste estudo que: } \\
t_{p u} \gg>>t_{n}\end{array}$ & \\
\hline $\begin{array}{l}\text { Coeficiente de Chuva para } \\
\text { cada mês do ano } \\
\text { segundo Lombardi Neto (1977) }\end{array}$ & $P_{a}=\frac{R_{c}}{P_{m}^{2}}=\frac{I_{v p s}}{t_{p u}} ;$ (Eq. 9) & \\
\hline (Eq.5) $R_{c}=P_{m}^{2} / P_{a}$ & $\begin{array}{l}\text { (Eq. 10) } \\
R_{c}=\frac{I_{v_{P}} \times P_{m}^{2}}{t_{p u}} \text {, dessa forma tem - se que: } \\
(\text { Eq. 11) } \\
E I_{30}=244,47 \times\left(\frac{I_{v p s} \times P_{m}^{2}}{t_{P u}}\right)^{0,508} \text { (Sul) } \\
(\text { Eq. 12) } \\
E I_{30}=126,76 \times\left(\frac{I_{v p s} \times P_{m}^{2}}{t_{P u}}\right)^{0,464} \text { (Centro) }\end{array}$ & \\
\hline
\end{tabular}

Tabela IV - Relação escalar da erosividade da chuva para estudos de vulnerabilidade e fragilidade ambientais associados a intensidade pluviométrica. Adaptado de Crepani et al. (2001).

RELAÇÃO ESCALAR DOS VALORES DE EROSIVIDADE DA CHUVA ENTRE VULNERABILIDADE À PERDA DE SOLOS E FRAGILIDADE AMBIENTAL

\begin{tabular}{|c|c|c|c|}
\hline $\begin{array}{c}\text { Intensidade Pluviométrica } \\
(\mathrm{mm} / \mathrm{mês})\end{array}$ & Vulnerabilidade & Fragilidade & $\begin{array}{c}\text { Grau de Vulnerabilidade / } \\
\text { Fragilidade }\end{array}$ \\
\hline$>525$ & 3,0 & 5 & Vulnerável / Muito Forte \\
\hline
\end{tabular}




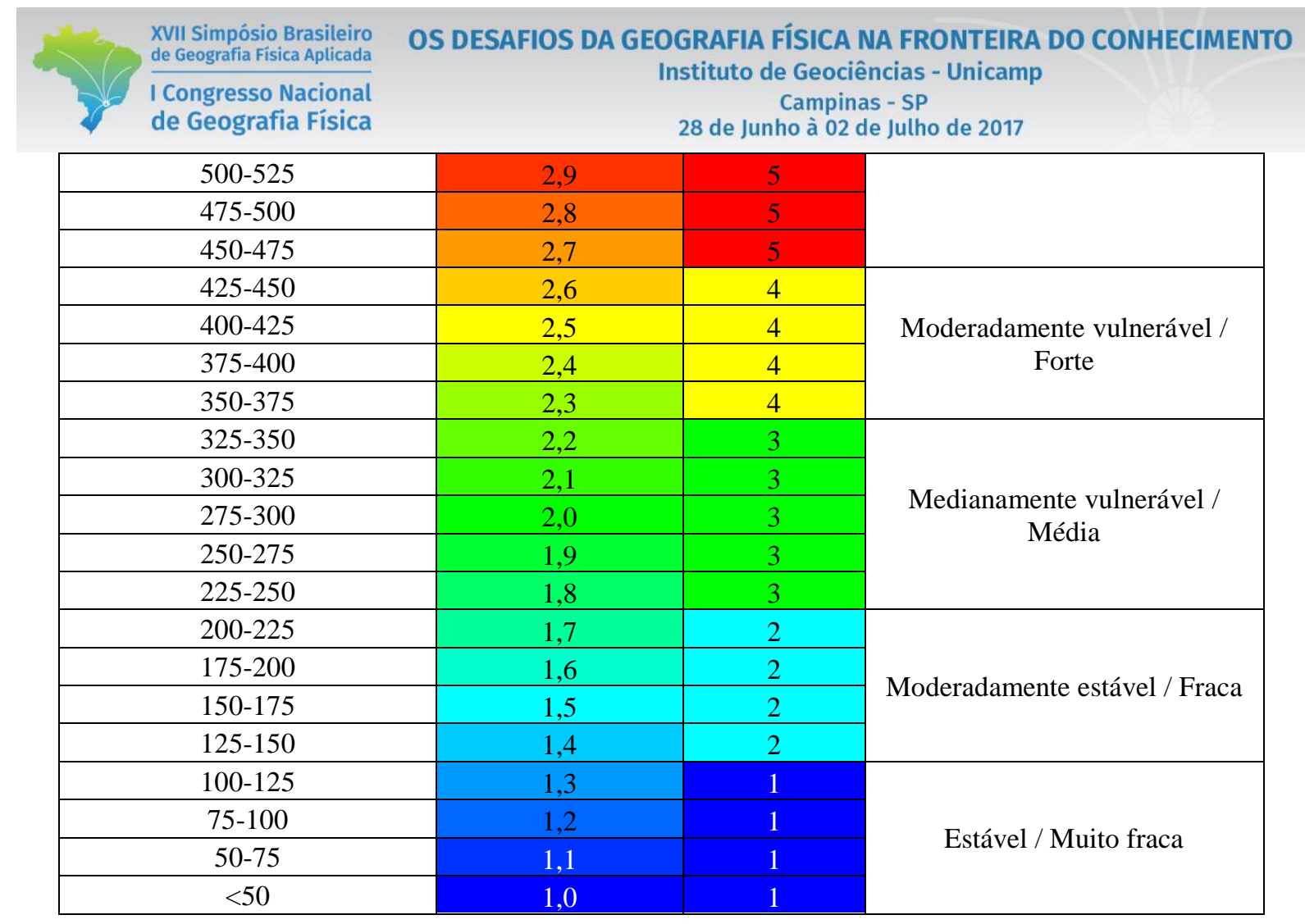

\section{Resultados e Discussão}

Para todas as análises interpretadas a seguir adverte-se que o produto gerado pela espacialização da vulnerabilidade ambiental associada à intensidade das chuvas possui uma relação escalar diretamente proporcional com o de fragilidade ambiental associada ao mesmo tema. Denotou-se que entre os parâmetros de potência dois (Figura 3, A1 e A2) e quatro (Figura 3, B1 e B2) a principal mudança foi que neste último houve uma maior aproximação dos dados declarados em cada estação pluviométrica, onde o contorno das isoetas se afastaram menos, tornando os valores mais locais, diferentemente do idw de $2^{\mathrm{a}}$ ordem, que distribuiu em maiores distâncias a faixa de valores das intensidades pluviométricas. Este fato demonstra que o compartamento desse interpolador é mais adequado para tratar dados cuja distância horizontal seja mais relevante do que a vertical, não sendo indicado portanto, para estudos dessa categoria, haja visto a pluviosidade ser mais influenciada pela variação altimétrica, que por sua vez, controla o gradiente de pressão atmosférica.

O spline (Figura 3, C1 e C2) delimitou maior quantidade de isoetas, uma vez que ampliou os valores escalares das intensidades pluviométricas, principalmente nos extremos da região, apresentando valores acima dos computados no SIG, este efeito foi também verificado no teste de superfície de tendência (trend) com potência de $2^{\mathrm{a}}$ ordem (Figura 3, D1 e D2). A diferença principal entre ambos: no primeiro o contorno 


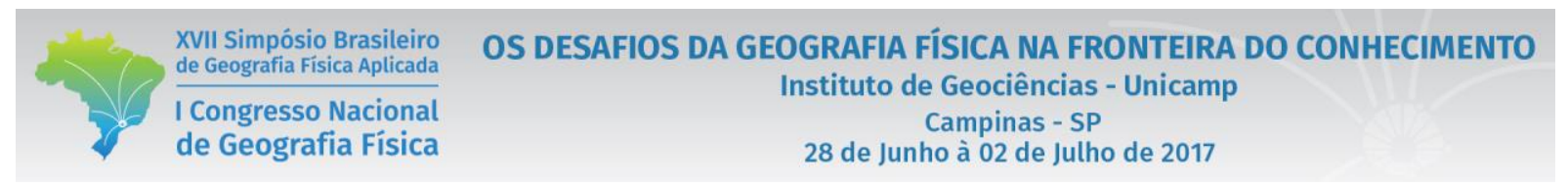

das isoetas apresenta maior contorção e, no segundo, as superfícies apresentam-se mais lisas. O topo-toraster (Figura 3, E1 e E2) demonstrou estrutura medianamente contorcida próxima à obtida pela krigagem (Figura 3, F1 e F2), onde o contorno das isolinhas neste último apresentou maior abrangência espacial no sentido oeste-leste dos intervalos escalares. Em ambos a faixa de valores declarada no SIG foi respeitada, sendo que a principal diferença deveu-se a quantidade de isolinhas espacializadas, onde o topo-to-raster mostrou-se mais fiel ao dado pluviométrico obtido de cada estação.

Dessa forma, entende-se que o topo-to-raster com enforce se adequa bem a realidade regional, uma vez que as isoetas geradas se ajustaram bem aos compartimentos morfoesculturais da área de estudo, assim como às características altimétricas desta região. Ressalta-se que Marcuzzo et al. (2011) também obtiveram os melhores resultados com esse interpolador, mapeando as chuvas de todo estado do Mato Grosso, utilizandose para isto 76 estações para a série histórica de 1977 a 2006. Nesse contexto, através do interpolador topoto-raster operacionalizou-se a espacilização dos parâmetros de precipitação média mensal e anual, do coeficiente de chuva e da erosividade, obedecendo as regiões pluviométricas homogêneas segundo Almeida (2009) apud Salton, Comunello e Fietz (2013).

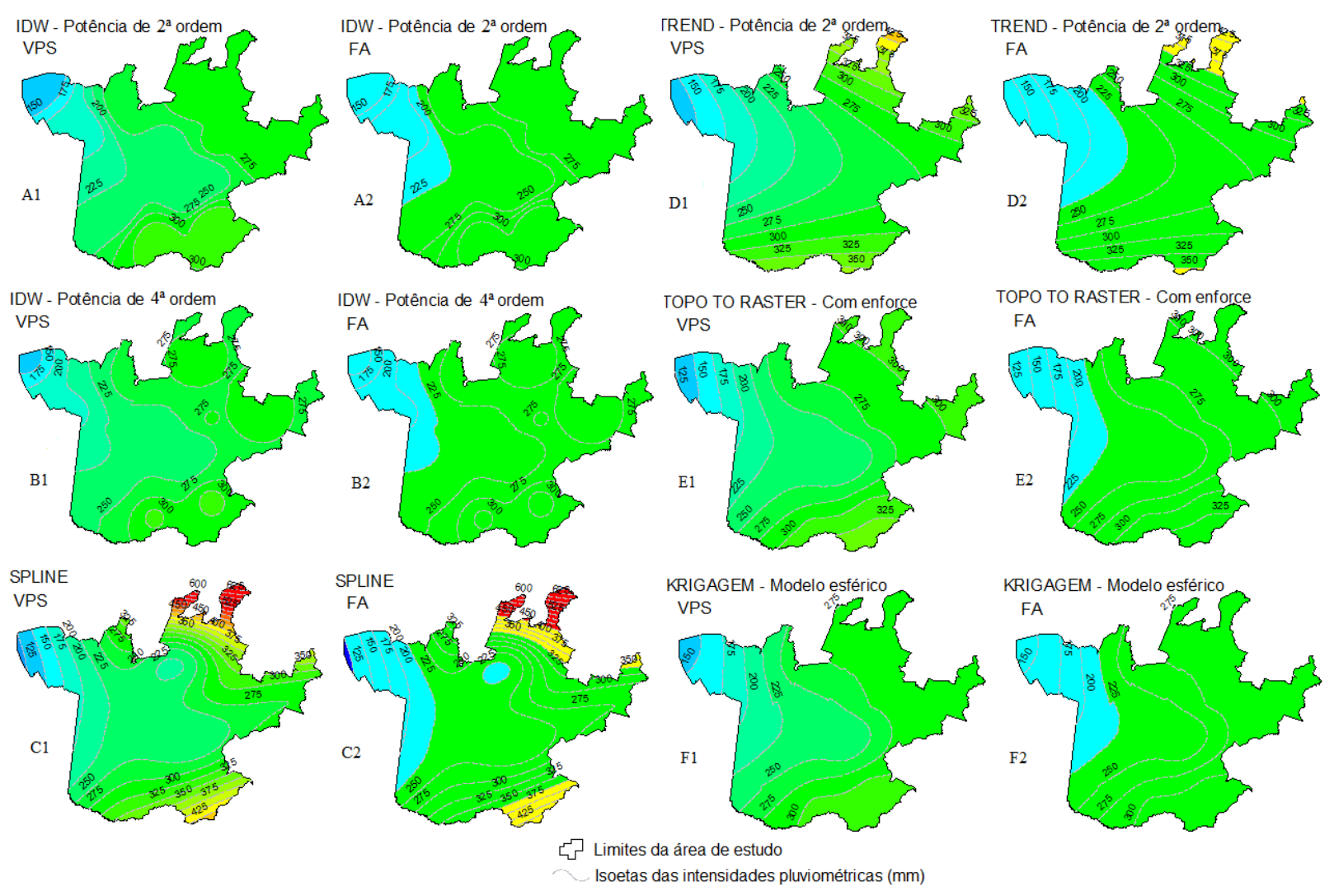




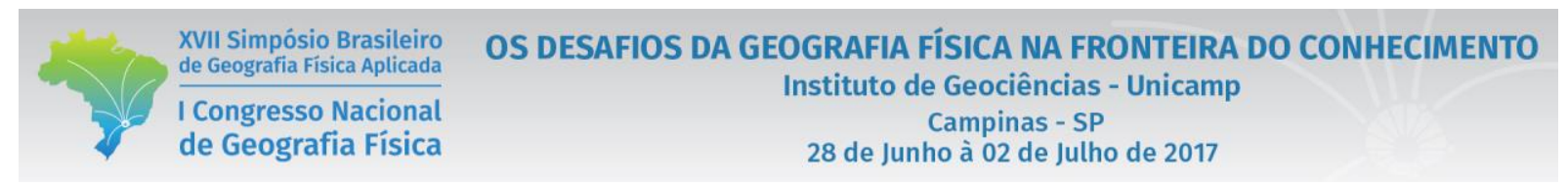

Figura 3 - Espacialização das vulnerabilidades (VPS) e fragilidades (FA) ambientais associadas às intensidades pluviométricas com os testes de interpolação nas categorias idw com potências de $2^{\mathrm{a}}$ e $4^{\mathrm{a}}$ ordens, spline, trend com potência de $2^{\mathrm{a}}$ ordem, topo-to-raster com enforce e krigagem modelo esférico. Observação: Os valores escalares das intensidades pluviométricas podem ser consultados na Tabela IV.

Baseando-se nos cartogramas obtidos (Figura 4) sugere-se que, tanto a precipitação média mensal (Figura 4a), quanto a anual (Figura 4b) são diretamente proporcionais a intensidade pluviométrica relacionada a erosividade segundo critérios de Crepani et al. (2001). Em todas as categorias de interpolação testadas, o padrão de curvatura das isoetas apresentaram valores ascendentes de intensidade pluviométrica no sentido oeste para leste, tal como configuraram-se as precipitações médias mensais e anuais, demonstrando que estas variáveis possuem dependência entre si. O coeficiente de chuva (Figura 4c) imprime contornos de isoetas mais contorcidos em relação as variáveis anteriormente analisadas e indica tendência de ascêndencia no sentido sudoeste para nordeste (NE/SW) configurando um padrão espacial intermediário entre as precipitações médias mensais e anuais com a erosividade.

A erosividade (Figura 4d) caracterizaram um padrão de ascendência de norte para sul nesta região, atestando que as equações de base radial que a modulam não apresentam proporcionalidade direta com a intensidade pluviométrica. Este fato atribui-se a situação de que na equação de erosividade, estimada para cada região pluviométrica homogênea, além de se considerar a intensidade de chuva em intervalo reduzido de 30 minutos, pondera também, o padrão de circulação atmosférico, o qual, pode atenuar ou acentuar o potencial da chuva erodir conforme a energia cinética da gota da chuva ao atingir o solo.

\footnotetext{
DOI - 10.20396/sbgfa.v1i2017.2046 - ISBN 978-85-85369-16-3
} 

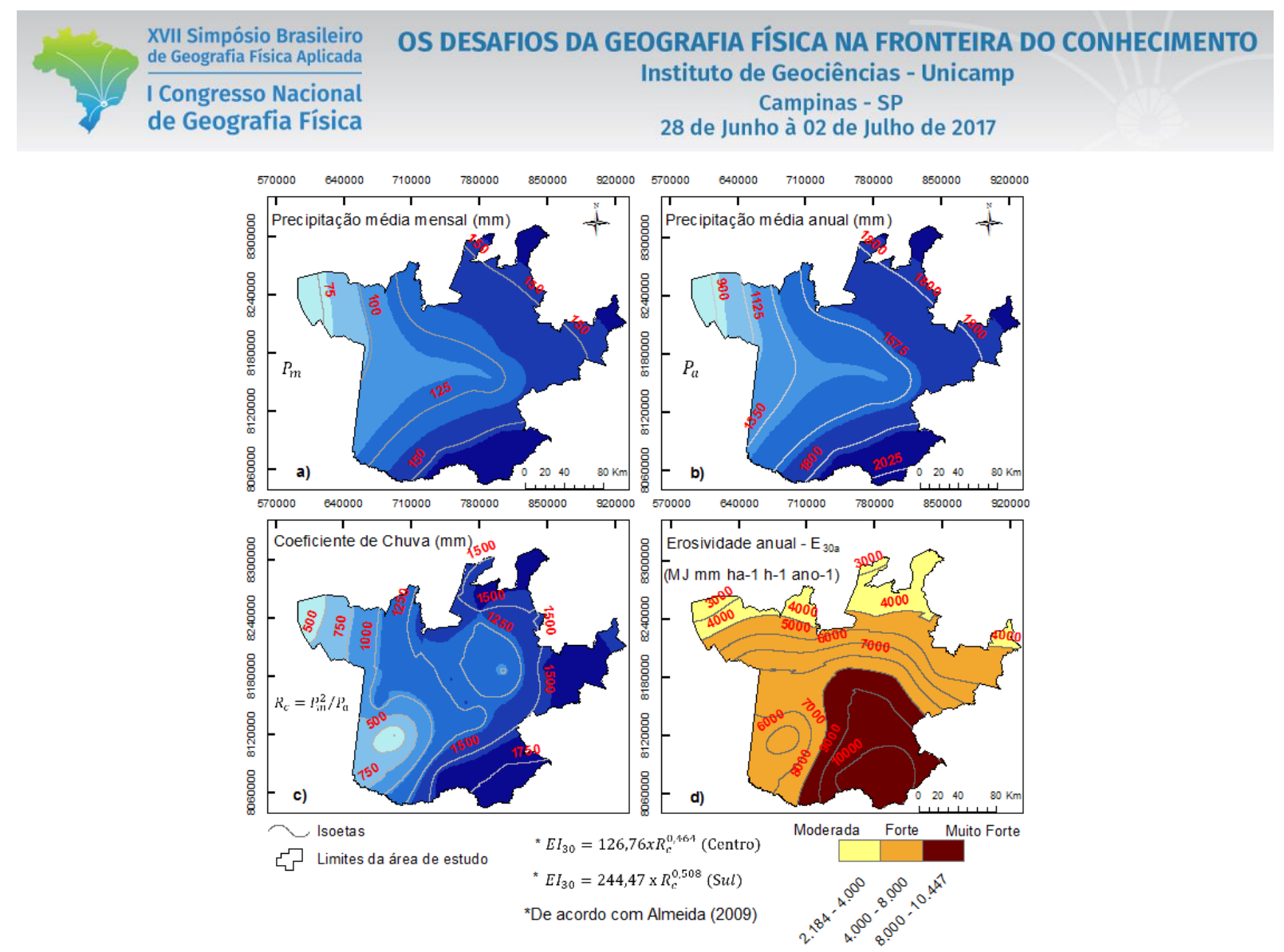

Figura 4 - Relação espacial entre precipitação média mensal, precipitação média anual, coeficiente de chuva e erosividade anual.

Neste cenário, obteve-se a relação entre as morfoesculturas existentes com os parâmetros de chuva analisados, onde os três diagnósticos apresetam cinco classes qualitativas de análise do ambiente.

Tabela V - Correlação entre classes de vulnerabilidade e fragilidade associadas à intensidade pluviométrica, com classes de erosividade de acordo com as morfoesculturas do relevo.

\begin{tabular}{cccc} 
Morfoesculturas & Vulnerabilidade & Fragilidade & Erosividade \\
\hline Planície Fluvial do Araguaia & $\begin{array}{c}\text { Moderadamente estável à } \\
\text { Medianamente Vulnerável }\end{array}$ & Fraca à Média & Forte \\
\hline $\begin{array}{c}\text { Áreas de Acumulação } \\
\text { Inundáveis do Araguaia }\end{array}$ & $\begin{array}{c}\text { Moderadamente estável à } \\
\text { Medianamente Vulnerável }\end{array}$ & Fraca à Média & Forte \\
\hline $\begin{array}{c}\text { Depressão Interplanáltica de } \\
\text { Rondonópolis }\end{array}$ & Medianamente vulnerável & Média & $\begin{array}{c}\text { Moderada, Forte } \\
\text { e Muito Forte }\end{array}$ \\
\hline $\begin{array}{c}\text { Planalto dos Guimarães } \\
\text { Planalto do Taquari-Alto } \\
\text { Itiquira }\end{array}$ & Medianamente vulnerável & Média & $\begin{array}{c}\text { Moderada, Forte } \\
\text { e Muito Forte }\end{array}$ \\
\hline Depressão Cuiabana & Moderadamente estável & Fraca & $\begin{array}{c}\text { Moderada, Forte } \\
\text { e Muito Forte }\end{array}$ \\
\hline
\end{tabular}




\section{Conclusão}

Verifica-se que o topo-to-raster se apresentou como o interpolador mais adequado na delimitação das isoetas, ajustando-se melhor aos compartimentos morfoesculturais e suas respectivas variações altimétricas. A vulnerabilidade e a fragilidade associadas a intensidade pluviométrica apresentaram-se diretamente proporcionais a precipitação média mensal e anual, enquanto que, o coeficiente de chuva e a erosividade demonstraram padrões distintos, onde entende-se que as equações condicionaram contornos de isoetas que não se relacionam diretamente com as morfoesculturas existentes entre planaltos, depressões interplanálticas e planícies.

Denota-se que tanto a vulnerabilidade, quanto a fragilidade ambientais associados a intensidade pluviométrica não são diretamente proporcionais aos índices de erosividade, podendo este último ser adicionado como tema nos prognósticos que utilizam-se da álgebra de mapas para sobreposições multitemáticas, tal como, aqueles executam em suas análises.

\section{Referências Bibliográficas}

CARVALHO, J. R. P., ASSAD, E. D., PINTO, H. S. Interpoladores geoestatísticos na análise da distribuição espacial da precipitação anual e de sua relação com altitude. Pesquisa Agropecuária Brasileira, v.47, n.9, p.1235-1242, set. 2012.

CREPANI, E; MEDEIROS, J. S; FILHO, P. H.; FloRENZANO, T. G; DUARTE, V; BARBOSA, C. C. F. Sensoriamento remoto e Geoprocessamento aplicados ao zoneamento Ecológico-Econômico e ao Ordenamento Territorial. Instituto Nacional de Pesquisas Espaciais (INPE), São José dos Campos, SP, 103 p. 2001.

GUIRRA, A. P. M., SANTOS, C. A., NOGUEIRA, C. E. A evolução metodológica de fragilidade ambiental no Brasil e seu aspecto transdiciplinar. IV Simpósio Nacional sobre Pequenas Cidades. Cidades pequenas: dinâmicas, escalas e redes. Ituiutaba, Minas Gerais, Brasil, v.1, p. 1-17, 22 a 25 de Novembro de 2016.

LUCAS, T. P. B., PLEC, D., ABREU, M. L., PARIZZI, M. G. Identificação de interpoladores adequados a dados de chuva a partir de parâmetros estatísticos. Revista Brasileira de Climatologia (versão eletrônica). Ano 09, v.13, jul./dez 2013.

MARCUZZO, F. F. N., ANDRADE, L. R., MELO, D. C. R. Métodos de interpolação matemática no mapeamento de chuvas do estado do Mato Grosso. Revista Brasileira de Geografia Física, v. 04, p.793-804, jan.2011.

MELLO, C. R., LIMA, J. M., SILVA. A. M., MELLO, J. M., OLIVEIRA, M. S. Krigagem e inverso do quadrado da distância para interpolação dos parâmetros da equação de chuvas intensas. Revista Brasileira de Ciências do Solo, v. 27: p. 925-933, 2003.

ROSS, J. L. S. Análise empírica da fragilidade dos ambientes naturais e antropizados. In: Revista do Departamento de Geografia FFLCH - USP, n 8, São Paulo, 1994.

ROSS, J. L. S. O registro cartográfico dos fatos geomórficos e a questão da taxonomia do relevo. In: Revista do Departamento de Geografia FFLCH - USP, n 6, São Paulo, 1992. 
SALTON, J. C., COMUNELLO, E., FIETZ, C. R. Estimativa de índices de erosividade da chuva para o Estado de Mato Grosso. Emprapa Agropecuária Oeste. Dourados, MS. 1ª Edição (versão eletrônica). p.46, 2013.

SECRETARIA DE ESTADO DE PLANEJAMENTO DO ESTADO DE MATO GROSSO. SEPLAN-MT. CAMARGO, L [Org.]. Atlas de Mato Grosso: abordagem socioeconômico-ecológica. Cuiabá, MT. Entrelinhas, 2011. $100 \mathrm{p}$.

SETTE, D. M. O Clima Urbano de Rondonópolis - MT. Faculdade de Filosofia, Letras e Ciências Humanas, Dissertação de Mestrado em Geografia Física. Universidade de São Paulo, 1996.

SOUZA, J. L. L. L., GOMES, T. S., DIAS, R. S., OLIVIERA, G. M. A., SANTOS, R. L. Avaliação de métodos de interpolação aplicados à espacialização das chuvas no território identidade Portal do Sertão / Bahia. Anais XV Simpósio Brasileiro de Sensoriamento Remoto - SBSR, Curitiba, PR, Brasil, p. 4295.30 de abril a 05 de maio de 2011.

TRICART, J. Ecodinâmica. Secretaria de Planejamento da Presidência da República. Fundação Instituto Brasileiro de Geografia e Estatística. Recursos Naturais e Meio Ambiente, 1, Diretoria Técnica, Rio de Janeiro, p.197,1977. 